\title{
La filosofía del Derecho de Robert Alexy como sistema*
}

\section{Robert Alexy's Philosophy of Law as System}

\section{Matthias Klatt}

Autor:

Matthias Klatt

Karl-Franzens-Universität Graz, Austria

matthias.klatt@uni-graz.at

https://orcid.org/0000-0002-9697-9975

Recibido: 24-1-2020

Aceptado: 13-3-2020

Citar como:

Klatt, Matthias, (2020). La filosofía del Derecho de Robert Alexy como sistema. Doxa. Cuadernos de Filosofía del Derecho, 43, pp. 219-252. https:// doi.org/10.14198/DOXA2020.43.09

\section{Licencia:}

Este trabajo se publica bajo una Licencia Creative Commons Atribución 4.0 Internacional.

\section{(c) (i)}

(C) Matthias Klatt

\begin{abstract}
Resumen
Los trabajos de Robert Alexy abarcan un amplio rango de temas relevantes: la teoría de la argumentación jurídica, el concepto y la validez del derecho y la teoría de los derechos fundamentales. En este artículo, explico en detalle cómo los múltiples elementos de la teoría del derecho de AleXY se encuentran conectados de modo coherente y sistemático. Después de reseñar los tres principales trabajos monográficos de AleXY, presento tres ideas sobre las cuales se ancla su obra: la tesis del caso especial, la pretensión de corrección y la posibilidad de una argumentación jurídica racional. Enseguida, analizo las relaciones e interconexiones entre estos tres trabajos. Finalmente, abordo el sistema de AleXY como un todo, sus elementos esenciales, su enfoque y carácter. En su conjunto, el presente artículo provee nuevas perspectivas sobre la claridad y profundidad del sistema de Alexy.
\end{abstract}

Palabras clave: Robert Alexy; naturaleza del derecho; pretensión de corrección; fórmula de Radbruch; no-positivismo

\begin{abstract}
The works of Robert Alexy span across a wide range of fundamental topics: the theory of legal argumentation, the concept and the validity of the law, and the theory of constitutional rights. In this article, I explicate in detail how the various elements of ALEXY's theory of law are connected coherently and systematically. After an overview of Alexy's three main works, I lay down three main overarching ideas that inspire all AlExy's work: the special case thesis, the claim to correctness, and the possibility of
\end{abstract}

\footnotetext{
* Este artículo fue originalmente publicado en inglés como «Robert Alexy’s Philosophy of Law as System», en M. Klatt (ed.), Institutionalized Reason: The Jurisprudence of Robert Alexy, Oxford: Oxford University Press, 1-26. Traducción al castellano de Héctor A. Morales Zúñiga. El autor agradece a Héctor Morales ZúNísa por la excelente y cuidadosa traducción que aquí se ofrece. El trabajo de traducción fue impulsado y hecho posible por un borrador elaborado por Augusto Fernando CARRILLO SALGADO a quien, también, agradece.
} 
rational legal argumentation. Next, I analyse the relations and interconnections between all three works. Lastly, I focus on the system of ALEXY's work as a whole, its essential elements, its approach and character. On the whole, my article provides new insights into the clarity and depth of Alexy's system.

Keywords: Robert Alexy; nature of law; claim to correctness; Radbruch formula; non-positivism.

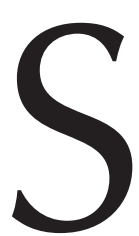

e ha observado frecuentemente que la obra de Robert Alexy forma un sistema. Mattias Kumm, por ejemplo, compara la obra de Alexy con la de DwOrKIN y afirma que «sus trabajos exhiben un enfoque holístico o sistémico para el estudio del derecho». ${ }^{1}$ Pavlakos, asimismo, elogia a Alexy por haber desarrollado «una filosofía sistemática que abarca la mayor parte de las áreas de la filosofía del derecho». ${ }^{2}$ El propio AlEXY, observando los vínculos entre sus principales trabajos, ha sugerido que "el resultado bien puede ser un sistema». ${ }^{3}$

Sin embargo, la forma en que este sistema debe explicarse no se ha abordado de manera eficaz. Esencialmente, este es el objetivo principal de la presente introducción. Por lo que respecta al concepto de «sistema», aplicaré un concepto kantiano, conforme al cual un sistema es una unidad estructurada por diversas partes ancladas en ideas generales. ${ }^{4}$

De acuerdo con Robert Alexy, el pensamiento jurídico-filosófico gira en torno a tres problemas: Primero: ¿Qué tipo de entidades dan forma al derecho y cómo se relacionan entre ellas? Esto conduce a los conceptos de norma y sistema normativo. Segundo: ¿Cómo debe entenderse la dimensión real del derecho? Esta pregunta es planteada por el positivismo jurídico y se refiere a la promulgación del derecho y a su eficacia social. Tercero: ¿Cómo debe entenderse la corrección o legitimidad del derecho? Este es el problema de la relación entre el derecho y la moral. ${ }^{5}$

AleXY combina su distinción tripartita sobre los problemas de la filosofía del derecho con cuatro tesis sobre su carácter. ${ }^{6}$ En primer lugar, el ámbito de estudio de la filosofía del derecho tiene una naturaleza general, pues no se limita a problemas jurídicos especiales, sino que abarca e incluye problemas filosóficos generales. En segundo lugar, la filosofía del derecho tiene una naturaleza específica, en tanto se ocupa -con especial atención- de problemas jurídico-filosóficos. En tercer lugar, la filosofía del derecho se relaciona con otras ramas de la filosofía, en particular, con la moral y la filosofía política. En cuarto lugar, la filosofía del derecho solo puede tener éxito, si estas

1. Kumm, 2004: 595.

2. Pavlakos, 2013: 17. Vid. también García Figueroa, 2009.

3. AleXY, 2007a: 2. Recientemente, AlEXy ha clarificado algunas estructuras de este sistema, vid. AlEXy, 2009a.

4. KANT afirma: «Entiendo empero por sistema la unidad de los múltiples conocimientos bajo una idea. Este es el concepto racional de la forma de un todo, en la medida en que mediante ese concepto se determina $a$ priori ante la extensión de lo múltiple, como el lugar respectivo de las partes». KANT, 2009: 713 (A833/B861).

5. Vid. Alexy, 2008c: 53 y s.; Alexy, 2007a: 8.

6. Alexy, 2008b: 41.

Doxa. Cuadernos de Filosofía del Derecho, (2020), 43, pp. 219-252 
tesis son combinadas. Por lo tanto, el concepto de filosofía del derecho de Alexy es un ideal comprehensivo, que requiere que todas estas cuestiones sean unidas de modo coherente. ${ }^{7}$ En otros términos, el concepto de filosofía del derecho de ALEXY conduce necesariamente al concepto de sistema.

La idea guía del sistema de Alexy -que se encuentra en el núcleo de su teoría del derecho- es la institucionalización de la razón. La teoría descansa en la afirmación de que el derecho comprende tanto una dimensión real o fáctica como una dimensión ideal o crítica. ${ }^{8}$ La reconciliación de estas dimensiones solo es realizable -si es posible del todo- por medio de la institucionalización de la razón. ${ }^{9}$

La conexión entre las dimensiones ideal y real del derecho qua institucionalización de la razón «comprende el postulado de un límite externo del derecho ..., las ideas de los derechos humanos y constitucionales, la democracia y el control judicial de constitucionalidad, la concepción del discurso jurídico como un caso especial del discurso práctico general y la teoría de los principios». ${ }^{10} \mathrm{La}$ forma política de la idea guía de la institucionalización de la razón es el constitucionalismo discursivo. ${ }^{11}$

Procederé en tres pasos. Primero, proporcionaré una visión general de las obras principales de AlEXY. Siguiendo el camino de sus tres principales monografías y sus artículos más importantes, esta panorámica reflejará los tres pilares de su trabajo. Posteriormente, identificaré las relaciones e interconexiones entre estos tres pilares. Lo anterior servirá para recolectar y analizar el material, preparando así el camino para el último paso, el cual se centrará en el sistema como un todo.

\section{LOS PRINCIPALES TRABAJOS DE ALEXY-UNA VISIÓN GENERAL}

La obra de AleXY puede ser ordenada de acuerdo a tres pilares: la teoría de argumentación jurídica, la teoría de los derechos fundamentales, y el concepto y la validez del derecho. Alexy aborda estos pilares en sus tres principales tratados.

Desde luego, estos tratados de AlEXY no representan el sistema completo de su filosofía del derecho, tal como la ha desarrollado a lo largo de los ańos. Por un lado, su sistema está en un constante proceso de refinamiento y desarrollo. Por otro lado, los principales tratados de Alexy han sido complementados con diversos artículos publicados en revistas especializadas. En consecuencia, mi visión general de sus obras principales comenzará con las monografías, pero a veces se basará también en las posteriores modificaciones y desarrollos realizados en artículos científicos. Seguiré a Alexy cronológicamente. Por lo tanto, iniciaré el estudio con su tesis doctoral, Teoría de la Argumentación Jurídica, para luego avanzar a su tesis de habilitación, Teoría

\footnotetext{
7. Ibid., 49.

8. AleXY, 2008d: 89.

9. Vid. AleXY, 2009a: 84.

10. AleXX, 2009b: 151.

11. Ibid.
}

Doxa. Cuadernos de Filosofía del Derecho, (2020), 43, pp. 219-252 
de los Derechos Fundamentales, y concluir con El Concepto y la Validez del Derecho. Posteriormente, realizaré algunas observaciones sobre el papel que estos trabajos desempeñan en su integración como un sistema.

\subsection{Teoría de la argumentación jurídica}

Antes de entrar en detalles, me gustaría dar una breve descripción de la historia de la publicación y recepción de este trabajo.

\subsubsection{Contexto de publicación}

La Teoría de la Argumentación Jurídica, tesis doctoral de AleXY, se publicó por primera vez en alemán en $1978 .{ }^{12}$ Su traducción al inglés apareció once años después. ${ }^{13}$ También se tradujo al español (1989), italiano (1998), portugués (2001 y 2005), chino (2002), lituano (2005) y coreano (2007).* Esta primera monografía refleja una tradición de pensamiento muy influyente y de gran alcance, a saber: la filosofía analítica del derecho. También forman parte de esta H.L.A. Hart, Hans Kelsen, Alf Ross y Neil MACCormick. ${ }^{14}$ Un eje rector de esta tradición consiste en determinar si, y hasta qué punto, el razonamiento jurídico puede ser una empresa racional y objetiva. ${ }^{15}$ ¿Pueden las proposiciones que abordan un problema jurídico estar justificadas racionalmente? De ser así, ¿cómo? Por lo tanto, los problemas de la función y relevancia de la objetividad, la lógica, la verdad y la corrección en el razonamiento jurídico tienen un papel importante en este enfoque. En aquellos días, estas preguntas estaban en boga en la filosofía del derecho de alcance internacional. La teoría de la argumentación jurídica, como área de la filosofía análitica del derecho, estuvo influenciada por los desarrollos de la teoría general de la argumentación y por el redescubrimiento del rol de la argumentación en la filosofía moral, ocupando una posición de liderazgo en la filosofía del derecho durante los años setenta y ochenta. ${ }^{16}$

Siguiendo una clasificación de Ulfrid Neumann, podemos distinguir tres corrientes dentro de la teoría de la argumentación jurídica: lógico-analítica, uno tópico-retórica y uno teórico-discursiva. ${ }^{17}$ La monografía de AlEXY destaca como ejemplo de esta última corriente, pero a la vez utiliza instrumentos de la corriente lógico-analítica. En la teoría alemana de la argumentación jurídica o -como era llamada en aquel

12. AleXY, 1978.

13. AlEXy, 1989.

* Nota del Traductor: En el año 2015 se publicó una versión en croata.

14. Vid. Kaufmann, 1992: 126-129. Sobre el papel de Peczenik en esta escuela de pensamiento, vid. KLatt, 2009.

15. Vid. Herget, 1996: 14.

16. Klatt, 2007b: 521; Hilgendorf, 2005: 39-42; Neumann, 1986: 1-6.

17. Neumann, 1986: 11 y ss.

Doxa. Cuadernos de Filosofía del Derecho, (2020), 43, pp. 219-252 
entonces- «metodología jurídica alemana», el trabajo de AleXY marcó un cambio significativo de paradigma. La metodología jurídica en la década del setenta había descubierto todas las debilidades del enfoque clásico de «interpretación como recuperación» (interpretation as retrieval), sin embargo, las consecuencias de aquello no fueron claras. Los académicos, en su mayoría, habían sido víctimas del indeterminismo jurídico. Estaban convencidos de que, dado que el texto de una norma no puede determinar su contenido ni su aplicación y que los prejuicios morales y políticos de los intérpretes influyen en todo el razonamiento jurídico, cualquier metodología era inútil. Así, debido a que el razonamiento jurídico no podía garantizar certeza absoluta, entonces debía ser abandonado por completo -o eso afirmaba la mayoría de los académicos. ${ }^{18}$

Por el contrario, Alexy, con la ayuda de instrumentos lógicos básicos, buscó demostrar que el razonamiento jurídico consiste en inferencias lógicas («justificación interna»), pero precisando que el propósito principal de la lógica en el razonamiento jurídico es revelar las premisas que demandan una justificación adicional («justificación externa»). ${ }^{19}$ Alexy, en este sentido, subrayó tanto la importancia de la lógica como sus límites. Por primera vez fue posible separar analíticamente aquellas partes del razonamiento jurídico que derivan principalmente de enunciados autoritativos, de aquellas partes que provienen de juicios de intérpretes individuales.

Otro aspecto significativo del trabajo de Alexy fue su sistema de veintiocho reglas y formas de argumentos jurídicos que, sistemáticamente y en detalle, marcaron claramente un avance respecto de la metodología jurídica anterior.

\subsubsection{Tres puntos principales}

Tres puntos principales de la primera monografía de AlEXY deben examinarse con mayor detalle. El propio Alexy los ha señalado como los aspectos más importantes de tal trabajo. Asimismo, estos tres puntos son los más relevantes para mi proyecto de reconstrucción de su sistema.

\subsubsection{Tesis del caso especial}

La tesis del caso especial de Alexy sostiene que el discurso jurídico es un caso especial del discurso práctico general. ${ }^{20}$ Esta tesis subraya dos puntos. ${ }^{21}$ Primero, el discurso jurídico es un caso del discurso práctico general, por ello es relacionado a cuestiones prácticas que conciernen a lo que es obligatorio, prohibido y permitido. Segundo, el discurso jurídico es un caso especial. Por eso no intenta responder preguntas prácticas

18. Vid. Alexy, 2003a: 327.

19. AleXY, 1997: 213 y ss.

20. Ibid., 206 y ss.

21. Alexy, 2007a: 2.

Doxa. Cuadernos de Filosofía del Derecho, (2020), 43, pp. 219-252 
en un sentido absoluto o general, sino más bien dentro del marco de un sistema jurídico específico. El marco jurídico impone restricciones al discurso práctico a través de sus normas vinculantes, precedentes y doctrinas derivadas de la dogmática. Por lo tanto, el discurso jurídico es un caso especial ya que, al contrario del discurso práctico general, tiene un carácter institucional y autoritativo.

Aun así, las restricciones impuestas por el marco jurídico no son tan poderosas como para anular completamente el impacto del discurso práctico general en la argumentación jurídica. Esto se debe a la textura abierta del derecho. En ciertos casos, no es posible decidir basándose únicamente en el material autoritativo. Las intenciones del legislador pueden ser poco claras, el lenguaje de la ley puede ser vago, las normas pueden estar en conflicto y los precedentes pueden ser revocados. Por lo tanto, el razonamiento jurídico se refugia en razones derivadas del discurso práctico general.

Han surgido muchas objeciones contra la tesis del caso especial, en particular por Jürgen Habermas en Facticidad y Validez. AleXy ha defendido su tesis en varios artículos. $^{22}$

\subsubsection{La pretensión de corrección}

De acuerdo con Alexy, la argumentación jurídica se encuentra decisivamente influenciada por una pretensión de corrección. ${ }^{23}$ Esto es, los razonamientos de las sentencias judiciales necesariamente pretenden ser correctos. Cualquier aserción jurídica (legal assertion) contiene necesariamente un compromiso discursivo - en el sentido de Robert Brandom- de que la decisión es procesal y sustantivamente correcta. ${ }^{24}$ Este compromiso posee tres elementos. ${ }^{25}$ El primero es la aserción jurídica. Esta, a su vez, se encuentra complementada por una exigencia de justificabilidad o fundamentabilidad. La argumentación jurídica es un juego de dar y pedir razones en el sentido de la pragmática normativa brandomiana. ${ }^{26}$ El tercer elemento de la pretensión de corrección es la expectativa de que toda aserción jurídica será aceptada como correcta por terceros. Sin embargo, estos tres elementos no dicen nada sobre el criterio de corrección. Esta cuestión es particularmente crucial en el contexto actual. Existen dos posibilidades importantes: el criterio puede limitarse al marco normativo de un sistema jurídico o ir más allá. La respuesta a este problema se deriva de la tesis del caso especial, que establece un vínculo necesario entre el discurso jurídico y el discurso práctico general. Dado este vínculo necesario, el compromiso contraido en virtud de una aserción

22. Los detalles de este debate no son de interés para el presente trabajo. Respecto a dichas objeciones, vid. Habermas, 2005: 274, 276, 305 y ss.; Neumann, 1986: 84 y ss.; Neumann, 1996: 417 y s.; Kaufmann, 1989: 20 y ss.; Günther, 1993; Braun, 1988: 259. Para las réplicas de Alexy, vid. Alexy, 1993; Alexy, 1997: 311 y ss.; Alexy, 1999. Vid. también Pavlakos, 1998; Dwars, 1992.

23. AleXY, 1997: 208.

24. Alexy, 2005b: 35; Brandom, 2005: 248; KLATt, 2017: 183-185.

25. AleXY, 2005b: 35.

26. Klatt, 2017: 173-178; Brandom, 2005: 37, 96, 108.

Doxa. Cuadernos de Filosofía del Derecho, (2020), 43, pp. 219-252 
jurídica no puede limitarse al dominio jurídico. Por lo tanto, la pretensión de corrección comprende tanto la corrección dentro del sistema jurídico como la corrección del propio sistema jurídico. ${ }^{27}$

\subsubsection{La defensa de la posibilidad de una argumentación jurídica racional}

El tercer punto principal de la Teoría de la Argumentación Jurídica se refiere a la posibilidad de una argumentación jurídica racional. Asumiendo una visión optimista, AleXY suscribe esta posibilidad. AlEXY rechaza que la argumentación práctica carezca de racionalidad, objetividad y corrección, anclando la correción teórico-discursiva entre los extremos de la objetividad pura y de la subjetividad pura. ${ }^{28} \mathrm{La}$ corrección teórico-discursiva se basa en una teoría procesal del discurso práctico, según la cual una proposición práctica es correcta si puede ser el resultado de un discurso racional. ALEXY construye el concepto de discurso racional mediante un sistema de veintiocho reglas y formas de argumentos, lo cual hace posible la demostración tanto de las condiciones como de los límites de la racionalidad discursiva del derecho..$^{29}$ Las condiciones, por un lado, se explican por las formas y reglas del discurso. Ellas deben seguirse para justificar el resultado racionalmente. Por otro lado, los límites de la racionalidad en el derecho se derivan del hecho de que el discurso jurídico no conduce a una única respuesta correcta. Más bien debe distinguirse entre tres posibles resultados del discurso jurídico. ${ }^{30}$ Basado en las reglas de este, los resultados pueden ser discursivamente necesarios, posibles o imposibles. Es decir, varias interpretaciones en conflicto podrían ser igualmente racionales al final del discurso jurídico.

\subsubsection{Historia de la recepción}

En el Post Scriptum a la segunda edición, en 1991, Alexy respondió las críticas formuladas en contra de la base teórico-discursiva de su monografía. ${ }^{31}$ De cien artículos publicados por Alexy, aproximadamente treinta están relacionados con temas de argumentación jurídica. De las veintisiete tesis doctorales dirigidas por Alexy, siete

27. Alexy, 2007a: 3. En su monografía, AlEXy había respondido este problema de una forma diferente, limitando la pretensión de corrección al marco jurídico, vid. Alexy, 1997: 208. Este cambio se debe al hecho de que después de la publicación de su monografía, ALEXY desarrolló la pretensión de corrección y la aplicó al derecho como un todo, vid. AlEXY, 2005b.

28. AleXY, 2001c: 672.

29. AleXY, 2007a: 3 y s.

30. Klatt, 2011: 515-517; AleXY, 1997: 202.

31. Este Post Scriptum no es parte de la primera edición en inglés. Nota DEL TRAdUCtor: la versión en español contiene el Post Scriptum o postfacio, vid. Alexy, 1997: 289 y ss. 
corresponden a tal ámbito. Además, la Teoría de la Argumentación Jurídica ha sido traducida a siete idiomas. ${ }^{32}$

En una entrevista con Manual AtienZa, Alexy hace referencia a dos puntos débiles de su primera monografía. ${ }^{33}$ Primero, la obra presupone un concepto de derecho nopositivista que, sin embago, no fue desarrollado completamente. En segundo lugar, la ponderación no es analizada como un método jurídico diferenciado. ${ }^{34}$ Ambas debilidades constituyen la base de las siguientes dos monografías, siendo, en efecto, más que compensadas.

\subsection{Teoría de los Derechos Fundamentales}

La segunda monografía de ALEXY, correspondiente a su tesis de habilitación, fue publicada en alemán en $1985 .{ }^{35}$ Además, fue traducida al español primero en 1993 y después en 2007, al inglés en 2002, al coreano en 2007, al portugués en 2008 y al polaco en 2010.* El papel de los derechos fundamentales en muchos sistemas jurídicos se caracteriza por cuatro factores. ${ }^{36}$ Primero, gozan del rango más alto en la jerarquía de normas. Segundo, su observancia es resguardada por una corte constitucional. Tercero, hacen referencia a asuntos de la mayor relevancia para las personas y la sociedad. Finalmente, exhiben una marcada textura abierta.

Es precisamente la mezcla de estos cuatro factores lo que da lugar a muchos problemas cruciales de la teoría de los derechos fundamentales. El tema central de la segunda monografía de ALEXY consiste en demostrar cómo estos problemas pueden ser resueltos, por un lado, distinguiendo dos tipos de normas, a saber: reglas y principios; $y$, por otro lado, explicando las consecuencias que se derivan de tal distinción teórica.

\subsubsection{Tres puntos principales}

\subsubsection{Reglas y principios}

La teoría de Alexy descansa en el análisis de los derechos fundamentales como principios, los cuales -en su opinión- son significativamente diferentes de las reglas. ${ }^{37}$ Es importante destacar que el concepto de principios de Alexy difiere del concepto

32. El reconocimiento internacional de la monografía de ALEXY comenzó con un artículo en inglés que destacó su importancia, vid. MaCCORMick, 1982.

33. Alexy, 2001c: 672.

34. Sin embargo, es importante destacar que la Teoría de la Argumentación Jurídica ya contiene reglas de prioridad que dependen de condiciones específicas, vid. Alexy, 1997: 196 y ss.

35. AlEXY, 1985.

* Nota del Traductor: El año 2012, una versión en italiano fue publicada.

36. Vid. Alexy, 2003b: 32-37.

37. Sobre el carácter crucial de esta distinción para la teoría de los derechos fundamentales, vid. ALEXY, 2008a: 63. 
convencional, el cual distingue los principios de las reglas por su nivel más general y su peso inferior. ${ }^{38}$ En contraste con el concepto convencional, Alexy sostiene que la diferencia no es de grado sino de tipo. Mientras que las reglas son aplicables en la forma todo-o-nada, los principios pueden cumplirse en diversos grados. Los principios son mandatos de optimización que «ordenan que algo sea realizado en la mayor medida posible, dentro de las posibilidades jurídicas y reales existentes». ${ }^{39}$

\subsubsection{Ley de ponderación y examen de proporcionalidad}

El carácter teórico-normativo de los derechos fundamentales como mandatos de optimización conduce al examen de proporcionalidad. ${ }^{40}$ Este examen suministra una prueba teórica sólida para evaluar lo que demanda un derecho fundamental en un caso concreto. El examen de proporcionalidad de un derecho fundamental se realiza en tres pasos: un examen de idoneidad, un examen de necesidad y un examen de proporcionalidad en sentido estricto. ${ }^{41}$ Los exámenes de idoneidad y necesidad juzgan lo que puede ser fácticamente posible. Ambos exámenes siguen la idea de «óptimo de Pareto» y tienen como objetivo evitar aquellas interferencias en derechos fundamentales que podrían ser evitadas sin costo para otros principios. ${ }^{42} \mathrm{El}$ tercer examen, proporcionalidad en sentido estricto, evalúa la optimización en relación a lo que es jurídicamente posible. El espacio de lo jurídicamente posible es determinado esencialmente por los principios antagónicos. Por lo tanto, el tercer examen requiere ponderar. La ponderación ha sido formulada por AleXY en su «ley de la ponderación»: "Cuanto mayor sea el grado de la falta de satisfacción o de la afectación de un principio, tanto mayor tiene que ser la importancia de la satisfacción del otro». ${ }^{43}$ Esta doctrina arroja luz sobre el hecho de que la teoría de los principios sobre los derechos fundamentales es, en esencia, una teoría de la ponderación. ${ }^{44}$

\subsubsection{La estructura de la ponderación y la formula del peso}

Diversos aspectos esenciales de la teoría de los derechos fundamentales han sido desarrollados y clarificados en los años subsecuentes a la publicación de la monografía,

38. Vid. Schauer, 1997: 911-922; Schauer, 2004: 69-72. Kumm contrasta la terminología de Alexy con diferentes sugerencias discutidas en la filosofía del derecho angloamericana, vid. Kumm, 2004: 576-578.

39. Alexy, 2008a: 67.

40. Entre la teoría de los principios y el examen de proporcionalidad existe una relación conceptualmente necesaria, vid. AleXY, 2019b: 82.

41. Vid. AleXY, 2006.

42. AleXY, 2007a: 5.

43. AleXY, 2008a: 138.

44. AleXY, 2007a: 5. Sobre la conexión necesaria entre los derechos fundamentales y la ponderación, vid. ALEXY, 2008a: 95-117. 
algunos por el propio AleXY y otros por académicos influidos por él. El desarrollo más significativo de la teoría es el relativo a la estructura de la ponderación. Alexy la ha elucidado en numerosos artículos, ${ }^{45}$ así como en el Post Scriptum a la edición en inglés de su Teoría de los Derechos Fundamentales. ${ }^{46}$ La "fórmula del peso" de Alexy yace en el centro de este nuevo análisis de la estructura de la ponderación. Esta fórmula define el peso concreto asignado a un principio que se encuentra en colisión con otro en un caso particular. Toma en cuenta los pesos abstractos de ambos principios, la intensidad de la interferencia en uno de ellos -i.e. el grado de falta de satisfacción-, así como el grado de seguridad de las premisas empíricas empleadas. ${ }^{47} \mathrm{La}$ fórmula del peso es un modelo matemático que emplea números, pero se basa en una escala triádica altamente intuitiva. Esta escala es la misma para valorar los pesos abstractos, las intensidades de la interferencia y los grados de seguridad. Distingue tres niveles: leve, medio y grave.

\subsubsection{Consecuencias y principales ventajas de la teoría de los principios}

De la estructura de los derechos fundamentales analizados por ALEXY se derivan una serie de consecuencias. Aquí solo se considerarán tres de ellas. Estas representan las ventajas principales de la teoría de los principios. La teoría de los principios conduce a una teoría de amplio alcance, caracteriza a la ponderación como racional e indispensable y ayuda al análisis de la relevancia, función y límites del control judicial de constitucionalidad.

\subsubsection{Alcance}

Hay dos enfoques opuestos acerca del alcance de los derechos fundamentales. El primero de ellos concibe el alcance y límites de los derechos fundamentales de forma acotada. El segundo interpreta el alcance y límites de los derechos fundamentales de manera amplia. ${ }^{48}$ La teoría de los principios de ALEXY respalda firmemente la segunda postura. La "teoría del alcance acotado" sería ventajosa solo si fuera posible trazar, sin ninguna dificultad, los límites entre los casos en que los derechos fundamentales deben ser protegidos y aquellos en que tal protección debe ser denegada. Esta condición se cumpliría solo si todos los casos de aplicación de derechos fundamentales fuesen fáciles. Sin embargo, debido a la existencia de muchos casos difíciles, en los que esta línea es siempre difícilmente trazable, la ponderación es inevitable. De acuerdo con la "teoría del alcance acotado", la ponderación tiene cabida solo en caso que deba definirse el alcance de un derecho. Esta teoría enfrenta la dificultad de justificar tal alcance sin

45. AleXY, 2014; AleXY, 2006: 5-11.

46. Alexy, 2008a: 529-546.

47. AleXY, 2014: 49-61.

48. Alexy, 2008a: 281-290; Alexy, 2019b: 88 y s.

Doxa. Cuadernos de Filosofía del Derecho, (2020), 43, pp. 219-252 
ninguna prueba. En contraste, la «teoría del alcance amplio» insiste en que cualquier argumentación en torno a derechos fundamentales debe prestar atención a argumentos rivales y, por lo tanto, requiere ponderación. Esta teoría suministra un mejor procedimiento paso-a-paso y evita negar ex-ante la posibilidad de la ponderación en cierta clase de casos. ${ }^{49}$

\subsubsection{La racionalidad y la necesidad de la ponderación}

La racionalidad de la ponderación es un tema controvertido. De acuerdo con RawLs, por ejemplo, podría concebirse una teoría de los derechos fundamentales como principios que estuviese comprometida con una ponderación intuitiva, lo que tendría como efecto mermar la fuerza vinculante del derecho. ${ }^{50}$ La ley de la ponderación de AleXY sitúa el tema de la racionalidad de la ponderación con mayor precisión. Esto ayuda a iluminar que la ponderación consta de tres pasos. ${ }^{51}$ En el primero se establece el grado de la falta de satisfacción o detrimento de un principio. En el segundo paso se determina la importancia de satisfacer el principio en conflicto. Finalmente, en el tercero, se dilucida si la importancia de satisfacer el último de los principios justifica la falta de satisfacción del primero. Por lo tanto, la racionalidad de la ponderación como un todo depende de la posibilidad de hacer juicios racionales sobre las intensidades de interferencia, el grado de importancia y la relación entre ellos.

$\mathrm{Al}$ descomponer la ponderación en tres pasos, AleXY no solo nos permite ver con claridad lo que significa la racionalidad de la ponderación, sino que también prepara el terreno para demostrar que, en rigor, la ponderación puede ser racional. La ley de la ponderación muestra que la argumentación en torno a derechos fundamentales sigue una estructura articulada, haciendo explícitas aquellas premisas que tienen que justificarse para afirmar que el resultado de la ponderación es, a su vez, justificado. Si el contenido definitivo de los derechos fundamentales debe ser determinado del modo más racional posible, el método de la ponderación es indispensable. ${ }^{52}$

\subsubsection{Derechos fundamentales y control judicial de constitucionalidad}

La teoría de los principios también tiene consecuencias para la dimensión institucional de los derechos fundamentales. ${ }^{53}$ Esta dimensión concierne a la posición de las cortes constitucionales y su papel en el control del poder legislativo y de otras autoridades públicas. La competencia de una corte constitucional para controlar la legislación

49. ALEXy, 2019b: 88 y s.

50. RAWLS, 1995: 44-50.

51. AleXY, 2006: 5.

52. Alexy, 2007a: 5.

53. Alexy, 2006: 11.

Doxa. Cuadernos de Filosofía del Derecho, (2020), 43, pp. 219-252 
parlamentaria es necesaria si los derechos fundamentales gozan de una prioridad sobre la legislación ordinaria. La ponderación se vincula a la dimensión metodológica del control judicial de constitucionalidad.

El problema más importante de la dimensión institucional de los derechos fundamentales consiste en justificar la competencia de las cortes constitucionales para determinar que actos del poder legislativo son inconstitucionales y declararlos consecuentemente nulos. ${ }^{54}$ Esta justificación es decisiva y compleja, pues necesariamente exige aclarar la relación entre derechos fundamentales y democracia. Entre los argumentos presentados en contra de la teoría de los principios, una postura se refiere a esta relación. BöCKEnförde ha sostenido que, en la teoría de AleXY, el poder legislativo pierde toda autonomía, debido a que su función se reduce simplemente a establecer lo que ya ha sido decidido por la constitución. En el Post Scriptum a la edición en inglés de su Teoría de los Derechos Fundamentales, Alexy demuestra que esta objeción presupone la existencia de una sola respuesta correcta a cualquier problema constitucional. ${ }^{55}$ Empero, esta posición no es asumida por la teoría de ALEXY; antes bien, su postura es consistente con la discreción substantiva del poder legislativo, pues Alexy ha desarrollado un sistema completo de poder discrecional que escapa de la esfera de acción del control judicial de constitucionalidad. Luego, la teoría de los principios analiza no solo la relevancia y función de tal control, sino que también sus límites.

\subsection{El argumento de la injusticia}

La monografía de ALEXY sobre el concepto y la validez del derecho fue publicado por primera vez en alemán en $1992 .{ }^{56}$ El objetivo de esta es defender una concepción no-positivista del derecho. Su mayor logro consiste en haber suministrado claridad al debate entre positivismo y no-positivismo. Para ello, Alexy trazó las distintas posiciones recurriendo a cinco categorías, dando lugar a un complejo sistema de posturas en la teoría del derecho.

La edición en inglés, traducida por Bonnie Litschewski Paulson y Stanley L. Paulson, apareció en 2002 como The Argument from Injustice: A Reply to legal Positivism. El trabajo ha sido traducido también al español (1994 y 1997), italiano (1997), coreano (2000), sueco (2005), árabe (2006), rumano (2008), eslovaco (2009) y portugués (2009). Todavía más importante, la monografía de Alexy ha conducido a dos debates con defensores del positivismo. El primer debate, con Andrei Marmor, tuvo lugar en la IVR World CONFerence en Granada el año 2005..$^{57}$ El segundo, con Joseph RAZ, siguió a este evento. ${ }^{58}$ AleXY se ha basado en las críticas de Marmor y

54. Ibid., 12.

55. Vid. AleXY, 2008a: 511 y ss.

56. AlEXy, 1992.

57. AleXy, 2005a.

58. Raz, 2013a; Alexy, 2013a.

Doxa. Cuadernos de Filosofía del Derecho, (2020), 43, pp. 219-252 
RAz para desarrollar y aclarar su posición sobre el concepto y la validez del derecho. ${ }^{59}$ Aquí presentaré la postura de ALEXY en su forma elaborada.

\subsubsection{La tesis de la conexión y la doble naturaleza del derecho}

El centro de la teoría no-positivista del derecho de AleXY es la tesis de la conexión. Por medio de ella se sostiene que hay una conexión necesaria entre la validez jurídica -i.e. corrección jurídica- y los méritos morales -i.e. corrección moral ${ }^{60} \mathrm{La}$ tesis de la conexión y su negación -i.e. la tesis de la separabilidad defendida por el positivismo jurídico- están abiertas a diferentes interpretaciones. Por lo tanto, diferentes versiones de ambas tesis son posibles. ${ }^{61}$ Alexy ha clarificado su propia postura en el área sistematizando las posibiles versiones dentro del no-positivismo. Esto contribuye al debate reciente entre positivismo jurídico incluyente y excluyente.

En particular, ALEXY distingue tres maneras a través de las cuales el no-positivismo puede determinar el impacto de los defectos morales en la validez jurídica. ${ }^{62}$ La primera posición afirma que cada defecto moral conduce a la invalidez jurídica. Por lo tanto, las normas moralmente defectuosas se encuentran excluidas del derecho. Esta posición extrema puede ser etiquetada como como «no-positivismo excluyente». La segunda posición sostiene que los defectos morales conducen a la invalidez jurídica solo en algunos casos. Un ejemplo de esta posición es la fórmula de Radbruch, de acuerdo con la cual los defectos morales conducen a la invalidez jurídica solo si ellos representan un caso de injusticia extrema. Esta posición puede ser denominada «no-positivismo incluyente». La teoría de ALEXY refleja esta posición. La tercera posición afirma que los defectos morales nunca afectan la validez jurídica. Esta es la posición de Kant. Por una parte, KANT basa la validez del derecho positivo sobre principios no-positivistas y sostiene que los defectos del derecho son dependientes de estos. Luego, la posición de Kant es no-positivista. Sin embargo, por otra parte, Kant enfatiza la dimensión real -en oposición a la ideal- del derecho al sostener que cada norma expedida autoritativamente y socialmente eficaz es jurídicamente válida. Así, de acuerdo con KANT, la relación en el derecho y la moral no es clasificante, sino únicamente cualificante. AleXY ha etiquetado esta posición como «no-positivismo superincluyente».

Desde el punto de vista de Alexy, el no-positivismo excluyente enfatiza indebidamente la dimensión ideal del derecho, en tanto que el no-positivismo superincluyente hace lo propio con la dimensión real del derecho. Por lo tanto, ambas posiciones fallan al reconocer lo que Alexy llama la doble naturaleza del derecho. De acuerdo con la tesis de la doble naturaleza del derecho, este comprende una dimensión factual,

59. El artículo más reciente es Alexy, 2008d. Nota del Traductor: vid. también Alexy, 2011a; Alexy, 2011b; Alexy, 2013b; Alexy, 2015; Alexy, 2017.

60. Alexy, 2008d: 79.

61. Sobre las posibilidades básicas, vid. ibid.

62. Ibid., 81-86.

Doxa. Cuadernos de Filosofía del Derecho, (2020), 43, pp. 219-252 
determinada por su expedición autoritativa y eficacia social, así como una dimensión ideal, definida por su corrección moral. Por lo tanto, la validez del derecho depende de hechos sociales y valores morales. ${ }^{63}$ Únicamente la segunda posición -el no-positivismo incluyente- hace justicia a la doble naturaleza del derecho, porque no afirma que los defectos morales siempre socaven la validez jurídica ni que nunca lo hagan.

En suma, Alexy defiende una versión particular de la tesis de la conexión basada en la tesis de la doble naturaleza del derecho, la cual puede denominarse «no-positivismo jurídico incluyente».

\subsubsection{Dos argumentos principales}

La tesis de Alexy de la doble naturaleza del derecho está basada en dos argumentos principales, los cuales se vinculan a la dimensión real e ideal respectivamente. ${ }^{64} \mathrm{Como}$ lo sostiene la «tesis de la dimensión real», el primer argumento establece que el derecho emplea coerción o sanciones. De la misma forma, como lo sugiere la «tesis de la dimensión ideal», el segundo argumento establece una relación necesaria entre el derecho y la moral.

\subsubsection{Coerción}

De acuerdo con Alexy, la relación necesaria entre derecho y coerción se refleja en dos factores.$^{65}$ Primero, esta relación es presupuesta por el uso de nuestro lenguaje. Segundo, dicha relación es necesaria para que el derecho cumpla con su función práctica, la cual consiste en suministrar certeza y eficacia jurídica. ${ }^{66}$

\subsubsection{Corrección}

Alexy sostiene que el argumento principal de la conexión necesaria entre el derecho y la moral y, por lo tanto, para la dimensión ideal del derecho como segundo aspecto de la

63. AleXy, 2007a: 6 y ss.

64. Sin embargo, lo más interesante es que los dos argumentos no están completamente separados el uno del otro. Por el contrario, se encuentran necesariamente relacionados, ya que la pretensión de corrección no solo sirve para establecer el vínculo sustantivo entre el derecho y la moral -como lo sostiene la tesis de la dimensión ideal-, sino que también para justificar la conexión necesaria entre el derecho y los principios de certeza y eficacia jurídica -como lo sostiene la tesis de la dimensión real. Al respecto, el argumento de la corrección es el más relevante de los dos. Por lo tanto, en el nivel más general, la tesis de la doble naturaleza del derecho está esencialmente basada en un solo argumento: el de la corrección. Vid. Alexy, 2008d: 91.

65. Ibid.

66. Sin duda, este argumento presupone una conexión necesaria entre los principios de certeza y eficacia jurídica, y el derecho. Dicha conexión se encuentra establecida por la tesis de la corrección. Por lo tanto, esta tesis no solo desempeña un papel en la dimensión ideal, sino también en la dimensión real. Vid. ibid. 
tesis de la doble naturaleza, es la pretensión de corrección del derecho. Originalmente, Alexy había analizado la pretensión de corrección en el contexto de la argumentación jurídica, relacionándola con actos institucionales tales como las decisiones judiciales. ${ }^{67}$ Posteriormente, Alexy ha extendido esta pretensión al derecho en general. ${ }^{68}$ En el contexto del concepto y la validez del derecho, esta versión extendida de la pretensión de corrección es la relevante.

El punto de vista de AlEXY de que el derecho necesariamente entabla una pretensión de corrección es demostrado mediante la referencia a contradicciones performativas. ${ }^{69}$ Esta pretensión conduce a una conexión necesaria entre el derecho y la moral, pues un juez que elige una interpretación moralmente errónea del derecho positivo, habiendo una interpretación moralmente correcta, no solo estaría tomando una decisión moralmente incorrecta, sino que también legalmente incorrecta. ${ }^{70}$

\subsubsection{No-positivismo incluyente y la perspectiva del participante}

Hasta ahora, al establecer una relación necesaria entre defectos morales y jurídicos, se ha demostrado una conexión cualificante entre el derecho y la moral. Sin embargo, el no-positivismo incluyente de ALEXY también propone una conexión clasificante. Esto se logra recurriendo a la fórmula de RADBRUCH la cual niega validez jurídica a normas extremadamente injustas. La tesis de la conexión por sí sola no puede justificar esta fórmula, ya que solo se refiere a los defectos jurídicos y no a la validez jurídica. Por lo tanto, se necesitan razones adicionales para justificar una relación clasificante entre el derecho y la moral. Estas razones, de acuerdo con Alexy, se encuentran en los derechos fundamentales. Su protección, desde un punto de vista moral, da lugar a la necesidad de trazar la relación clasificante entre el derecho y la moral, tal como lo sostiene la fórmula de RADBRUCH. ${ }^{71}$

Con esta línea argumentativa, AlEXy integra argumentos normativos al debate sobre lo que es el derecho. Tales argumentos podrían ser fácilmente aducidos en debates sobre lo que el derecho debería ser. No obstante, el tema en cuestión es la disputa entre positivismo y no-positivismo sobre la naturaleza del derecho. Por lo tanto, el uso de argumentos normativos sobre lo que debería ser el derecho no es claro de inmediato. Sin embargo, lo que a primera vista podría verse como un error de categoría resulta esencial para que la doble naturaleza del derecho no se entienda correctamente. ${ }^{72} \mathrm{La}$ doble naturaleza del derecho solo se refleja correctamente en una teoría del derecho si se toma en cuenta no solo la perspectiva del observador, sino que también la del

67. Vid. supra: «1.1.2.2. La pretensión de corrección».

68. Alexy, 2005b; Alexy, 2004: 41 y ss.

69. AleXY, 2004: 41-45.

70. Alexy, 2008d: 93 y ss.

71. Ibid., 94; AleXY, 2004: 63.

72. AlEXy, 2008d: 96.

Doxa. Cuadernos de Filosofía del Derecho, (2020), 43, pp. 219-252 
participante. Mientras el observador pregunta cómo se adoptan las decisiones judiciales, refiriéndose de esta manera a la dimensión real del derecho, el participante pregunta cuál es la respuesta jurídica correcta, aludiendo así a la dimensión ideal del derecho. Combinando ambas perspectivas, Alexy tiene una respuesta al positivismo. Alexy integra el deber ser con el ser del derecho. Desde el nivel metodológico o filosófico, la tesis de la doble naturaleza descansa en la integración de estas dos categorías del discurso que a menudo son vistas como separadas o, incluso, como irreconciliables. Ciertamente, el positivismo entiende que estas categorías se hallan separadas. ${ }^{73}$ Sin embargo, AlexY insiste en su integración. La integración de las categorías del ser y deber ser -piensa ALEXY- provee una explicación más robusta y compleja del concepto de derecho que la proveída por el positivismo jurídico. En suma, por lo tanto, la respuesta de AleXY al positivismo jurídico es que este falla al integrar la perspectiva del participante en la teoría. Es la perspectiva del participante la que da lugar a una conexión necesaria entre lo que es y lo que debe ser el derecho. ${ }^{74}$

\section{RELACIONES E INTERCONEXIONES}

Entre los aspectos notables del trabajo de AleXY se encuentra el hecho de que, a pesar de la amplitud de los campos cubiertos, los pilares de su teoría permanecen vinculados estrechamente entre sí. Hablando en términos generales, cuanto más amplia es la sustancia, mayor es el riesgo de perder estos vínculos. $\mathrm{Al}$ analizar las relaciones e interconexiones entre los tres trabajos principales de AlEXY, mostraré que su teoría no es vulnerable en este sentido.

\subsection{El concepto de derecho y la argumentación jurídica}

La relación entre la argumentación jurídica y el concepto de derecho desempeña un papel importante en la Teoría de la Argumentación Jurídica. De hecho, en rigor, esta relación es la base de la teoría. Esta fundamental relación puede desarrollarse atendiendo a la pretensión de corrección del derecho.

\subsubsection{La tesis del caso especial}

La Teoría de la Argumentación Jurídica se basa en la tesis del caso especial. De acuerdo con la tesis del caso especial, el discurso jurídico es un caso especial del discurso práctico

73. Raz, 2013b; AleXy y Marmor, 2005: 752 y s.

74. La tesis de la conexión se justifica además con una versión particular de la pretensión de corrección, a saber: la tesis de la injusticia extrema. Vid. Alexy, 2007a: 7. 
general. ${ }^{75}$ La tesis del caso especial muestra que la argumentación jurídica tiene una doble naturaleza. Esto es, por un lado, se arraiga en el lado autoritativo, institucional o real del derecho. La argumentación jurídica se establece en un contexto institucional específico y está sujeta a normas, precedentes y a la doctrina jurídica. Por lo tanto, las razones autoritativas poseen un papel especial en la argumentación jurídica. Por otra parte, la argumentación jurídica también se encuentra relacionada con el lado ideal del derecho. En los casos difíciles, en los cuales debido a la textura abierta del derecho no es proporcionada una decisión clara basada solo en el lado autoritativo, la argumentación jurídica debe incluir al discurso práctico general. La tesis del caso especial tiene como objetivo integrar estos dos aspectos del derecho en una teoría de la argumentación jurídica. $^{76}$

El punto decisivo es este: es la combinación de estos dos lados lo que genera una conexión necesaria entre el derecho y la moral. Por lo tanto, la tesis del caso especial conduce necesariamente a una concepción no-positivista del derecho. ${ }^{77} \mathrm{Al}$ respecto, la tesis del caso especial representa la dimensión teórico-argumentativa -o metodológicade la tesis de la doble naturaleza del derecho. La tesis del caso especial hace explícitas las consecuencias teórico-argumentativas de la doble naturaleza del derecho y, de ese modo, establece una conexión intrínseca entre la argumentación jurídica y el concepto de derecho.

\subsubsection{La pretensión de corrección del derecho}

La conexión intrínseca entre la argumentación jurídica y el concepto de derecho nopositivista, como ha sido demostrada con la ayuda de la tesis del caso especial, puede analizarse más detalladamente al observarse la tesis de la pretensión de corrección. Esta tesis afirma que las normas individuales, las decisiones judiciales individualmente consideradas y el sistema jurídico en su conjunto erigen una pretensión de corrección. ${ }^{78}$ Esta afirmación -en la forma del argumento de la corrección- desempeña un rol decisivo en el trabajo de ALEXY sobre el concepto y la naturaleza del derecho. ${ }^{79}$ Además, dado que la corrección implica justificabilidad, esta tesis también es central para la teoría de la argumentación jurídica. Por lo tanto, la pretensión de corrección se complementa necesariamente con una pretensión de justificabilidad o fundamentabilidad ${ }^{80}$; y la justificabilidad es el tema central de la teoría de la argumentación jurídica.

75. AleXY, 1997: 206-213.

76. AleXY, 1999: 24.

77. Alexy, 2001c: 672. Vid. Alexy, 2007a: 3.

78. Alexy, 2004: 41 y ss.

79. De hecho, el argumento de la corrección es la base de los otros dos argumentos principales contra el positivismo jurídico, vid. ibid. 41.

80. Alexy, 2005b: 35; Alexy, 2004: 82. 
La pretensión de corrección genera una conexión entre el discurso jurídico y el discurso práctico general, ya que esta incluye a la corrección moral y, en consecuencia, a la argumentación moral. ${ }^{81}$ Cuando un juez afirma que la decisión dictada es correcta sostiene, primero, que la decisión interpreta el derecho positivo correctamente y, segundo, que el derecho positivo en sí mismo es correcto desde el punto de vista de la moralidad crítica. ${ }^{82}$ La consecuencia teórico-argumentativa de lo anterior es que la pretensión de corrección y justificabilidad no le permite al juez abstenerse de ofrecer argumentos para colmar las lagunas del derecho. Si bien los argumentos autorizados por la ley positiva puedan agotarse, la pretensión de justificabilidad persiste. Por lo tanto, el juez necesita recurrir a la argumentación práctica general.

No obstante, esta conexión teórico-argumentativa entre el derecho y la moral no conduciría a ninguna conexión teórico-conceptual entre ellos, si el positivismo jurídico estuviera en lo correcto. Es posible para un positivista estar de acuerdo en este punto con Alexy y aun negar cualquier conexión conceptual necesaria entre el derecho y la moral. Tal es el caso de Joseph RAZ, quien coincide en que «los jueces están sujetos a la moral de todas formas». ${ }^{83}$ Raz está de acuerdo, además, en que los tribunales deben aplicar argumentos provenientes de la etapa ejecutiva, con su fuerza autoritativa -consideraciones de derecho positivo- y de la etapa deliberativa, que incluye razones de carácter moral. ${ }^{84}$ En suma, estas observaciones de RAZ se encuentran perfectamente de acuerdo con la tesis del caso especial y la pretensión de corrección de Alexy. Sin embargo, RAz limita el derecho a la etapa ejecutiva, en tanto que Alexy incorpora la etapa deliberativa al concepto de derecho.

De todo esto se sigue que, si RAz tuviera razón, la pretensión de corrección no conduciría a una conexión necesaria entre la teoría de la argumentación jurídica y el concepto no-positivista de derecho. Por lo tanto, se requieren argumentos adicionales. Alexy los extrae del ejemplo mencionado anteriormente. En un caso en que los argumentos autoritativos dejan espacio a dos interpretaciones plausibles, mientras que un argumento moral individual favorece una interpretación y rechaza la otra, el juez debe seguir la interpretación favorecida por el argumento moral. ${ }^{85}$ Por el contrario, si un juez escoge seguir la interpretación alternativa, la cual es moralmente defectuosa, esta decisión -piensa AleXY- es también una decisión jurídica, aunque defectuosa desde el punto de vista jurídico. Lo anterior se explica pues la argumentación moral se encuentra engarzada en la pretensión de corrección entablada por la decisión. Para RAz, en cambio, esta decisión, aun cuando resulte moralmente defectuosa, sería jurídicamente correcta.

Aquí, el punto no es resolver la cuestión basándose en los méritos de los argumentos ofrecidos en el debate entre AlEXY y Raz. Antes bien, las observaciones sobre su

81. AleXY, 2003a: 327.

82. AleXy, 2007a: 2; Alexy, 2008d: 93 y s.

83. RAZ, 2013c: 296.

84. Raz, 1995: 147 y ss.

85. AleXY, 2008d: 93 y s. El ejemplo presupone que solamente un argumento adicional se halla disponible.

Doxa. Cuadernos de Filosofía del Derecho, (2020), 43, pp. 219-252 
disputa deberían ser suficientes para demostrar cómo -según AleXY- la pretensión de corrección -sobre los cimientos de una teoría de la argumentación- produce una conexión necesaria entre el derecho y la moral, reuniendo así al concepto de derecho con la teoría de la argumentación jurídica. ${ }^{86}$

\subsection{El concepto de derecho y la teoría de los derechos fundamentales}

Si bien la relación entre el concepto del derecho y la teoría de la argumentación jurídica puede ser clara, la conexión entre el concepto del derecho y la teoría de los derechos fundamentales lo es menos. ${ }^{87}$ Sin embargo, el último vínculo es tan próximo como el primero. Acá, se considerarán cuatro aspectos de este. Los dos primeros revelan una relación de justificación mutua entre los derechos fundamentales y un concepto nopositivista de derecho. El tercer aspecto se centra en una conexión metodológica. El cuarto recurre a los derechos fundamentales para justificar una relación clasificante entre el derecho y la moral.

\subsubsection{Los derechos fundamentales como un argumento contra el positivismo juridico}

AleXY utiliza a los derechos fundamentales para justificar su concepto no-positivista de derecho. De acuerdo con Alexy, los derechos fundamentales son principios -i.e. mandatos de optimización- y, como tales, deben distinguirse de las reglas. Esta distinción teórico-normativa conduce a una conexión necesaria entre el derecho y la moral a través de tres tesis: la «tesis de la incorporación», la «tesis de la moral» y la «tesis de la corrección». ${ }^{88} \mathrm{La}$ tesis de la incorporación sostiene que todo sistema jurídico necesariamente comprende principios jurídicos. La tesis de la moral, a su vez, afirma que la incorporación de principios conduce a una conexión necesaria entre el derecho y la moral crítica. Finalmente, la tesis de la corrección establece una conexión necesaria entre el derecho y la moral correcta. Los detalles de este argumento no son de interés aquí. Es suficiente advertir que la distinción teórico-normativa entre reglas y principios se usa como base de uno de los principales argumentos contra el positivismo jurídico.

\subsubsection{No-positivismo jurídico y justificación de los derechos fundamentales}

Las preguntas sobre la justificación de los derechos fundamentales pueden entenderse al menos de dos maneras. La primera concierne a la justificación de los derechos fundamentales en tanto parte de un sistema jurídico, es decir, si acaso son jurídicamente

86. Vid. Alexy, 2005b: 47; Alexy, 2007a: 2 y ss.

87. Para una perspectiva crítica, vid. КосH, 1988: 157, 160; Poscher, 2007: 64.

88. Alexy, 2004: 75-85. 
válidos. La segunda manera es más elemental. Esta concierne a la cuestión de si los derechos fundamentales existen per se, es decir, independiente de cualquier sistema jurídico en particular.

De acuerdo con Alexy, el no-positivismo jurídico desempeña un papel vis-à-vis la segunda comprensión de la justificación. La justificación de la existencia de los derechos fundamentales per se-cree ALEXY-requiere un discurso moral. ${ }^{89}$ Es imposible justificar la existencia de derechos fundamentales per se sin emplear argumentos morales -como argumentos distintos de los meros argumentos jurídicos. Por lo tanto, los derechos fundamentales pueden entenderse como postulados morales elementales. La justificación de los derechos fundamentales per se, como una especie de discurso moral, establece una conexión necesaria entre el derecho y la moral. ${ }^{90}$ Luego, en la teoría de ALEXY, el no-positivismo jurídico y la teoría de los derechos fundamentales están entrelazados.

Vale la pena señalar que este vínculo no es tan cercano como para hacer que el derecho y la moral sean idénticos. Por el contrario, los derechos fundamentales a menudo impiden que las consideraciones morales desempeñen un papel demasiado importante en un sistema jurídico. ${ }^{91}$ De este modo, la relación entre no-positivismo jurídico y derechos fundamentales tiene dos caras. Mientras las consideraciones morales son necesarias para justificar los derechos fundamentales, estos derechos evitan al mismo tiempo una invasión generalizada de la moral sobre el sistema jurídico. Precisamente este punto revela la forma en que los derechos fundamentales funcionan como una importante puerta entre el derecho y la moral y, en rigor, como un medio para equilibrar las problemáticas tensiones entre ellos.

\subsubsection{Ponderación y pretensión de corrección}

También existe una conexión metodológica entre el concepto de derecho no-positivista de Alexy y los derechos fundamentales. Esta conexión puede ser explicada mediante la referencia al debate entre Alexy y Habermas.

Los derechos fundamentales se hacen efectivos mediante el método de la ponderación. Habermas ha objetado a Alexy que es imposible combinar en una teoría única la pretensión de corrección con el método de la ponderación, ya que la ponderación no sigue un esquema "correcto-incorrecto». Este argumento se basa en la suposición de que no hay estándares racionales para decidir si un resultado particular de la ponderación es correcto. ${ }^{92}$

89. AleXy, 2007b.

90. En rigor, el positivismo jurídico puede incluir principios morales como los derechos fundamentales en el sistema jurídico y aun defender la tesis de la separación (e.g. el positivismo jurídico incluyente de Jules CoLEMAN o Matthew Kramer). Sin embargo, esta posición representa un ajuste al positivismo jurídico para hacerlo coincidir con la realidad de los sistemas jurídicos constitucionales modernos. Más que un simple ajuste, una teoría no-positivista es capaz de suministrar a estos sistemas jurídicos una base real. Vid. AleXY, 2001c: 673.

91. Ibid.

92. Habermas, 1995: 1531 y ss.; Habermas, 2005: 332. 
Si Habermas tuviera razón, entonces, o bien el método de la ponderación o la pretensión de corrección tendrían que ser abandonados. ${ }^{93}$ ALEXY muestra en su análisis de la estructura de la ponderación que existen estándares racionales que la gobiernan. Esto prueba la posibilidad de combinar la pretensión de corrección del derecho con el método de la ponderación. No es suficiente, sin embargo, para establecer una conexión necesaria entre los dos. Por lo tanto, Alexy va un paso más allá, sosteniendo que el método de la ponderación no solo es compatible con la pretensión de corrección, sino que, de hecho, la requiere. ${ }^{94}$

\subsubsection{Derechos fundamentales y la fórmula de RADBRUCH}

La fórmula de RADBRUCH, en su forma abreviada, afirma que la injusticia extrema no es derecho. ${ }^{95}$ La fórmula desempeña un rol importante en la justificación del concepto de derecho no-positivista de AleXy. A su vez, los derechos fundamentales hacen lo propio en la justificación de tal fórmula y, por lo tanto, indirectamente, en la justificación del concepto no-positivista de derecho.

Aquí hay que distinguir dos aspectos. El primero se remonta a una objeción planteada por H. L. A. HART, quien argumentó que la fórmula era prescindible, ya que la injusticia de la ley podía enfrentarse de formas distintas a la de revocar su carácter jurídico. Por ejemplo, un parlamento podría derogar un cuerpo normativo injusto mediante una ley retroactiva. ${ }^{96}$ ALEXY muestra que la mera posibilidad de una ley retroactiva no es suficiente para demostrar la prescindibilidad de la fórmula de RADBRUCH. ${ }^{97}$ Cuando el parlamento erradamente no ejerce este poder, se requiere la fórmula de RADBRUCH para declarar inaplicable la ley injusta en un tribunal. El juez no puede decidir sobre la base de una ley injusta, ya que esto sería irreconciliable con la protección de los derechos fundamentales. Por lo tanto, ALEXY utiliza los derechos fundamentales para demostrar la indispensabilidad de la fórmula de RADBRUCH -respondiendo así al argumento de HART.

Ya se ha mencionado el segundo aspecto de la relación entre el concepto de derecho no-positivista incluyente de Alexy y los derechos fundamentales. Este se deriva del hecho de que el mensaje central de la fórmula tiene un carácter clasificante. La fórmula invalida ciertas normas, excluyéndolas del dominio del derecho. Es precisamente este carácter clasificante el que es esencial para apoyar el concepto no-positivista incluyente de derecho de Alexy. De acuerdo con Alexy, la protección de los derechos

\footnotetext{
93. Vid. Alexy, 2019a: 69 y ss.; Alexy, 2019c: 110 y ss.

94. Alexy, 2019a: 70.

95. Vid. AleXY, 2001a: 76.

96. Vid. HART, 1962: 46-48.

97. AleXy, 2004: 62-64.
}

Doxa. Cuadernos de Filosofía del Derecho, (2020), 43, pp. 219-252 
fundamentales da lugar a la necesidad de establecer la relación clasificante entre el derecho y la moral -tal como es defendida por la fórmula de RADBRUCH. ${ }^{98}$

\subsection{Argumentación jurídica y derechos fundamentales}

En su monografía sobre argumentación jurídica, AleXX se preocupa por la transición desde una norma jurídica a una decisión judicial. En esta obra, Alexy no analizó el concepto de norma en sí misma. Aquel fue, sin embargo, uno de los cometidos de su monografía sobre derechos fundamentales. ${ }^{99}$ El análisis de ALEXY de la estructura de los derechos fundamentales conduce naturalmente a la práctica institucional de la ponderación y, por lo tanto, de regreso a la teoría de la argumentación jurídica. Vale la pena señalar que un elemento importante de la teoría de los derechos fundamentales ya estaba contenido -al menos sustancialmente- en la Teoría de la Argumentación Jurídica; a saber, las reglas que prescriben qué reglas, bajo ciertas circunstancias, deben tener prioridad sobre otras. ${ }^{100}$

Dado que los derechos fundamentales deben interpretarse a través de argumentos jurídicos, están necesariamente vinculados con la argumentación jurídica. ${ }^{101} \mathrm{La}$ teoría de la argumentación jurídica de Alexy es esencialmente teórico-discursiva. En su opinión, la relación entre la teoría del discurso y los derechos fundamentales es «estrecha, profunda y compleja». ${ }^{102}$ Se pueden distinguir tres dimensiones de esta relación: una dimensión filosófica, que se refiere a la justificación o fundamento de los derechos fundamentales; una dimensión jurídica, referida a la interpretación y aplicación de estos derechos; y una dimensión institucional, que alude a la institucionalización de los derechos fundamentales y al control judicial de constitucionalidad.

\subsubsection{La dimensión filosófica: la justificación teórico-discursiva de los derechos fundamentales}

En cuanto a la dimensión filosófica, ALEXY ofrece una justificación teórico-discursiva de los derechos fundamentales. Como lo sugiere Alexy, la justificación es tanto explicativa como existencial. Es explicativa en la medida que, siguiendo la filosofía trascendental de KANT, intenta hacer explícitas las condiciones necesarias, aunque implícitas, de la práctica humana. ${ }^{103}$ Es existencial en la medida que descansa en la naturaleza discursiva de los seres humanos. ${ }^{104}$ Las reglas del discurso de Alexy hacen explícitos los valores

98. AleXy, 2008d: 94 y s.; AleXy, 2004: 63.

99. AleXY, 2003a: 328.

100. AleXY, 1997: 196 y ss.

101. Vid. Alexy, 1999.

102. Alexy, 2010: 29.

103. Ibid., 37 y s.

104. Ibid., 38 y s.

Doxa. Cuadernos de Filosofía del Derecho, (2020), 43, pp. 219-252 
de la libertad e igualdad. Ellas iluminan el hecho de que las prácticas discursivas -los juegos de dar y pedir razones, en la terminología de BRANDOM-contienen valores. Los detalles de esta discusión no son de interés aquí. ${ }^{105}$ Más bien, es suficiente apuntar que, en la dimensión filosófica, ALEXY usa la teoría del discurso para justificar los derechos básicos, estableciendo así una "conexión sustantiva intrínseca» ${ }^{106}$ entre la teoría del discurso y los derechos fundamentales.

\subsubsection{La dimensión jurídica: subsunción y ponderación}

La dimensión jurídica se refiere a la interpretación y aplicación de los derechos fundamentales. Aquí también encontramos una estrecha conexión entre la teoría de la argumentación jurídica de ALEXY y su teoría de los derechos fundamentales.

El análisis de ALEXY de los derechos fundamentales se basa en la distinción entre reglas y principios. Esta distinción es de teoría de las normas. La teoría de los principios, no obstante, tiene también un lado metodológico, el cual está intrínsecamente conectado a la teoría de las normas. ${ }^{107}$ La ponderación presupone que las normas que se ponderan tienen la estructura de principios, y clasificar las normas como principios necesariamente invoca el método de la ponderación.

Desde una perspectiva teórico-argumentativa, se requiere la teoría de los principios para obtener una elaborada teoría de la ponderación como forma racional de argumentación. ${ }^{108}$ Por lo tanto, la teoría de los principios es un aspecto importante del proyecto general de la teoría de la argumentación jurídica; en particular, en lo que respecta al análisis de las condiciones de la argumentación jurídica racional.

En el nivel más general, Alexy distingue dos formas de razonamiento jurídico: las reglas son aplicadas por medio de la subsunción y los principios son aplicados por medio de la ponderación. La estructura de ambas formas es diferente. Mientras que la subsunción sigue un esquema deductivo -desarrollado conforme a las reglas de la lógica-, la ponderación sigue la fórmula del peso -entendida de acuerdo con las reglas de la aritmética. ${ }^{109}$ En lo que se refiere a la dimensión jurídica, la Teoría de los Derechos Fundamentales es una especie de secuela de la Teoría de la Argumentación Jurídica, que se enfoca en un tipo diferente de norma, los principios.

Dado que ambas formas de razonamiento jurídico están relacionadas con diferentes tipos de normas, pudiera parecer que deberían estar completamente separadas. Este no es el caso. Puede demostrarse lo anterior, asumiendo el doble carácter de las normas de derechos fundamentales. ${ }^{110}$ Este doble carácter deriva del hecho de que, aun cuando las

105. Klatt, 2017; Alexy, 1995 a.

106. Alexy, 2007a: 4.

107. AleXY, 2001b: 197.

108. AleXy, 2007a: 4 y ss.

109. Vid. AleXY, 2014. Para una perspectiva crítica, vid. BROżEK, 2013: 423.

110. Vid. Alexy, 2019b: 85 y ss.

Doxa. Cuadernos de Filosofía del Derecho, (2020), 43, pp. 219-252 
normas de derechos fundamentales son entendidas inicialmente como principios, estos deben ser integrados en normas de derecho constitucional que tienen la forma de reglas. La forma más general de estas reglas es: «para todos los casos en que la intervención estatal provoca que una acción protegida sea imposible y esto no se encuentra justificado, la intervención del Estado se encuentra constitucionalmente prohibida». Esta es una regla en el sentido de la distinción teórico-normativa de ALEXY: si su condición es satisfecha, entonces la consecuencia jurídica debe ser aplicada. Al mismo tiempo, la ponderación está imbuida en esta regla, ya que el antecedente de la regla hipotéticamente formulada comprende el examen de proporcionalidad. Este doble carácter revela que cualquier subsunción bajo una norma de derechos fundamentales presupone la ponderación. ${ }^{111}$ Esto cuenta como la relación más estrecha entre la argumentación jurídica y la teoría de los derechos fundamentales.

Una segunda relación más técnica se deriva del hecho de que la ponderación como tal se basa en proposiciones vinculadas al grado de interferencia, la importancia de los pesos abstractos y los grados de confiabilidad de las premisas empíricas. Estas proposiciones tienen que justificarse mediante argumentos, que en cuanto tales no son argumentos específicos de la ponderación. Más bien, todos los argumentos jurídicos pueden usarse para justificar estas proposiciones. ${ }^{112}$ Por lo tanto, cualquier ponderación de principios requiere argumentación jurídica ordinaria -como se analiza en la teoría de la argumentación jurídica de Alexy. «La ley de la ponderación dice qué es lo que tiene que fundamentarse racionalmente». ${ }^{113}$ De nuevo: el discurso resulta ser la base de la aplicación de los derechos fundamentales, estableciendo así una conexión necesaria entre la teoría de la argumentación jurídica y la teoría de los derechos fundamentales. ${ }^{114}$

\subsubsection{La dimensión institucional: democracia discursiva y control judicial de constitucionalidad}

La dimensión institucional se refiere a la institucionalización de los derechos fundamentales en un sistema jurídico específico. Aquí, la teoría del discurso requiere una forma organizativa específica de la democracia que podría etiquetarse «democracia discursiva». ${ }^{115}$ Los valores de libertad e igualdad son fundamentales para la teoría del discurso y tienen que ser incorporados en un sistema jurídico, si se pretende que la argumentación jurídica sea lo más racional posible. En segundo lugar, para evitar -tanto

111. Ibid., 86.

112. Ibid., 89 y s.

113. AleXY, 2008a: 144.

114. AleXY, 2007a: 6. Vid:: «El modelo de la ponderación, basado en la teoría de los principios ... [vincula] la estructura formal de la ponderación a una teoría de la argumentación jurídica, que incluye una teoría de la argumentación práctica general». ALEXy, 2008a: 146. Vid. también: «la Fórmula de Subsunción y la Fórmula de Peso tienen el mismo soporte, en tanto que los juicios permanecen en ambos casos iguales». Alexy, 2014: 60.

115. AleXy, 2010: 40.

Doxa. Cuadernos de Filosofía del Derecho, (2020), 43, pp. 219-252 
como sea posible- violaciones de los derechos fundamentales, la teoría del discurso requiere la institucionalización del control judicial de constitucionalidad, lo cual en sí mismo debe tener un carácter discursivo. ${ }^{116}$ ALEXY elabora este aspecto en el último acápite de su Teoria de los Derechos Fundamentales. ${ }^{117}$ La argumentación en base a derechos fundamentales está determinada en cierta medida por las reglas y formas del discurso. Aun así, persiste una significativa brecha de racionalidad. Esto lleva a la necesidad de tomar decisiones autoritativas sobre derechos fundamentales y, por lo tanto, a la necesidad de institucionalizar alguna forma de corte constitucional. AleXY va un paso más allá al proponer -en general- que «solo dentro del marco de un sistema jurídico, la razón práctica que vincula la argumentación y la decisión de manera racional, puede lograr su realización». ${ }^{118}$ Los detalles de este argumento no se considerarán aquí. Únicamente es importante señalar que la teoría del discurso juega un papel en la institucionalización de los derechos fundamentales y del control judicial de constitucionalidad.

\section{EL SISTEMA COMO UN TODO}

Para construir el sistema de la filosofía del derecho de Alexy como un todo, primero analizaré algunos elementos clave y su relevancia para el sistema en su conjunto. En segundo lugar, reflexionaré brevemente sobre algunas formas de caracterizar el sistema y el enfoque general de Alexy.

\subsection{Elementos clave}

El intento de identificar elementos clave de un sistema presupone un concepto claro de «elemento clave». Consideraré como elementos clave en el sistema de Alexy precisamente aquellos elementos que han tenido un efecto decisivo en los tres pilares mencionados en este trabajo. Los elementos clave deberán articular una base general desde la cual los detalles de los tres pilares pueden ser explicados.

Los candidatos a elementos clave del sistema de ALEXY son seis: la idea de racionalidad discursiva en el derecho, la tesis del caso especial, la tesis de la corrección, la tesis de los principios, la tesis de la injusticia extrema y la tesis de la doble naturaleza. Es posible reducir aún más esta lista, ya que la tesis del caso especial y la tesis de la corrección pueden estimarse como complementos de la tesis del discurso, mientras que la tesis de la injusticia extrema puede entenderse como un complemento de la tesis de la doble naturaleza. Por lo tanto, en el nivel más general, nuestra lista contiene tres elementos clave: la tesis del discurso, la tesis de los principios y la tesis de la doble naturaleza. No sorprende que estos tres elementos se originen en los tres pilares de la filosofía del

116. Ibid..

117. Alexy, 2008a: 508 y s.; vid. Alexy, 2006: 15-18.

118. Alexy, 2008a: 509.

Doxa. Cuadernos de Filosofía del Derecho, (2020), 43, pp. 219-252 
derecho de Alexy. La cuestión de una categorización adecuada no se considerará más aquí. Más bien, mi punto principal es que los tres elementos juegan un papel decisivo en los tres pilares por igual. A continuación, demostraré esto con respecto a cada uno de los tres elementos clave.

\subsubsection{La tesis de la doble naturaleza y su relevancia para el sistema}

La tesis de la doble naturaleza combina una dimensión institucional, autoritativa o real del derecho con una dimensión crítica o ideal. Se origina en el pilar vinculado al concepto y a la naturaleza del derecho. Es la expresión crucial de la tesis de la conexión en el no-positivismo incluyente. Sin embargo, la tesis de la doble naturaleza también tiene consecuencias para los otros dos pilares. AlEXY aplica esta tesis al derecho en general, pero también a la argumentación jurídica en particular. Como este indica, la argumentación jurídica tiene una doble cara. ${ }^{119}$ Por un lado, está conectada con el carácter institucional, autoritativo o real del derecho, pues el razonamiento jurídico per se tiene lugar en un entorno institucional que genera decisiones judiciales que se hacen cumplir, cuando es necesario, por el poder. Por otro lado, la argumentación jurídica está relacionada con el carácter ideal del derecho. Esto puede advertirse por el hecho de que la argumentación jurídica implica al razonamiento moral, lo cual no es sino la tesis de la doble naturaleza en su dimensión teórico-argumentativa, que se expresa claramente en la tesis teórico-discursiva del caso especial. Esta última tesis, en palabras de Alexy, es el intento de llegar a una teoría adecuada de la argumentación jurídica que cubra ambas dimensiones de la tesis de la doble naturaleza. ${ }^{120}$

La relación entre la teoría del discurso y la tesis de la doble naturaleza también se puede demostrar de una manera diferente. La teoría del discurso analiza las condiciones de la argumentación jurídica racional mediante veintiocho reglas y formas de discurso. Sin embargo, también nos permite ver los límites de la racionalidad en el derecho, ya que estas reglas y formas no siempre conducen a una única respuesta correcta. Por el contrario, en muchos casos, dejan abierto un ámbito de decisiones meramente posibles (en términos discursivos) - generalmente, decisiones en conflicto. Este ámbito de desacuerdo discursivamente posible, y por lo tanto racional, nos obliga a introducir reglas jurídicas positivas -i.e. formales- sobre cómo alcanzar y hacer cumplir una decisión. Por lo tanto, los límites de la teoría del discurso explican la necesidad de la positividad del derecho. A este respecto, la tesis de la doble naturaleza comienza con la dimensión ideal en la forma de corrección y discurso, y conduce, solo en segunda instancia, a la dimensión fáctica en la forma de positividad y eficacia. ${ }^{121}$

Mientras que la relevancia de la tesis de la doble naturaleza del derecho para la argumentación jurídica y el concepto de derecho es clara, su papel vis-á-vis la teoría de

119. Alexy, 1999: 24.

120. Ibid.

121. Vid. Alexy, 2007a: 3.

Doxa. Cuadernos de Filosofía del Derecho, (2020), 43, pp. 219-252 
los derechos fundamentales es más complejo. De acuerdo con Alexy, la tesis de la doble naturaleza del derecho exige la institucionalización de la razón. La institucionalización de la razón provee a la doble naturaleza del derecho una forma política sustancial. ${ }^{122}$ La forma política que mejor concuerda con la tesis de la doble naturaleza es una democracia liberal. La justificación de esto deriva de la dimensión jurídico-argumentativa de la tesis de la doble naturaleza. Las condiciones del discurso jurídico demandan que la democracia y los derechos fundamentales formen parte del sistema jurídico. ${ }^{123}$ Entonces, la forma política de la democracia liberal se desarrolla completamente por la teoría de los principios de los derechos fundamentales. La teoría de los principios hace posible una ponderación racional y una comprensión de la discreción de las autoridades públicas. También hace posible el establecimiento de una línea demarcatoria entre las competencias del parlamento y de la corte constitucional. El objetivo general de la institucionalización de la razón qua democracia liberal es conciliar la dimensión real e ideal del derecho. ${ }^{124}$ Por lo tanto, los detalles de la teoría de los principios y el análisis de los derechos fundamentales están estrechamente relacionados con la tesis de la doble naturaleza del derecho.

\subsubsection{La tesis del discurso y su relevancia para el sistema}

La idea de la racionalidad discursiva en el derecho está relacionada esencialmente con la pretensión de corrección. Esta pretensión enlaza la tesis del discurso y la doble naturaleza del derecho. Un segundo puente entre las dos es la tesis del caso especial, la cual se origina en la teoría del discurso pero conduce a una conexión necesaria entre el derecho y la moral. Ambos puentes ya han sido analizados en esta función previamente. Lo mismo es cierto para el vínculo entre la tesis del discurso y el análisis de los derechos fundamentales: este vínculo puede demostrarse en las tres dimensiones -i.e. filosófica, política y jurídica. En la dimensión filosófica, los derechos fundamentales se justifican con la ayuda de la tesis del discurso. En la dimensión política, la teoría del discurso especifica una forma política particular para la institucionalización de los derechos fundamentales. En la dimensión jurídica, la teoría de la ponderación, como parte de la tesis de los principios, contribuye a la teoría de la argumentación jurídica en su conjunto.

\subsubsection{La tesis de los principios y su relevancia para el sistema}

La tesis de los principios tiene al menos cuatro vínculos importantes con la posición de Alexy sobre el concepto de derecho. Los derechos fundamentales qua principios 
derrotan al concepto positivista del derecho. Segundo, el no-positivismo jurídico es esencial para la justificación de los derechos fundamentales. Tercero, la pretensión de corrección requiere la ponderación como método apropiado para aplicar los principios jurídicos. Finalmente, los principios jurídicos son empleados para justificar el carácter clasificante de la tesis de conexión -tal como lo sostiene la fórmula de RADBRUCH.

La relevancia de la tesis de los principios en el campo de la argumentación jurídica se puede ver en las tres dimensiones analizadas con anterioridad.

\subsection{Enfoque y carácter}

La tarea, aquí, es conceptualizar el sistema como un todo mediante la identificación de su carácter subyacente. La primera declaración de AlEXY sobre el carácter de su sistema de filosofía del derecho se puede encontrar en su introducción a una colección de artículos publicados en 1994. Allí declara:

Los once artículos publicados aquí varían tanto en sus objetos como en su presentación. Sin embargo, ellos se mantienen unidos por el método analítico y las ideas liberales de autonomía y universalidad. Si mi suposición es correcta, en el sentido de que el método y las ideas antes mencionados están estrechamente relacionadas entre sí, entonces podríamos hablar de un «liberalismo analítico». ${ }^{125}$

El liberalismo analítico desmiente la afirmación de que el trabajo de Alexy es puramente formal y carece de ideas sustanciales. De acuerdo con AleXY, cualquier sistema jurídico mínimamente elaborado implica eo ipso valores morales fundamentales en forma de derechos básicos. Al mismo tiempo, estos derechos básicos impiden una identificación demasiado rígida entre el derecho y las convicciones morales. Por lo tanto, el liberalismo analítico puede interpretarse como un intento de resolver las tensiones existentes entre el derecho y la moral. En cualquier caso, muestra claramente que la filosofía de AleXY no es en absoluto puramente formal.

Posteriormente, ALEXY identifica la relación entre el derecho y la razón como el núcleo de su trabajo. ${ }^{126}$ Esta relación es profunda y compleja. Culmina en lo que se puede etiquetar como «institucionalización de la razón». ${ }^{127}$ Varios aspectos de la relación entre derecho y razón pueden ser distinguidos. El primero es un aspecto conceptual. La razón juega un papel importante en la determinación del concepto de derecho: exige la transformación de los derechos humanos en derecho positivo. Además, sirve para establecer la fórmula de RADBRUCH; a saber, que la injusticia extrema no puede ser derecho válido. Por lo tanto, la razón excluye la famosa afirmación de Kelsen, de que cualquier contenido puede ser derecho. ${ }^{128} \mathrm{El}$ segundo aspecto es metodológico: la

125. AleXY, 1995b: 10.

126. AleXY, 2001c: 684 .

127. Ibid., 685.

128. Vid. Alexy, 2007a: 3.

Doxa. Cuadernos de Filosofía del Derecho, (2020), 43, pp. 219-252 
razón se interpreta como argumentación. Por lo tanto, las reglas y formas del discurso jurídico son establecidas qua razón. ${ }^{129}$ Empero, no alcanzan definitividad en cada caso particular. Por ello, es necesario complementar las reglas de argumentación mediante estructuras de toma de decisiones. En este punto entra en juego el tercer aspecto de la relación entre derecho y razón, a saber, el aspecto político. La forma política de la institucionalización de la razón es el "constitucionalismo discursivo». ${ }^{130}$ AleXY lo describe como «una empresa para institucionalizar la razón y la corrección». ${ }^{131}$ El constitucionalismo discursivo proporciona exactamente aquellas estructuras de toma de decisiones que, desde un punto de vista metodológico, son necesarias para la transformación de resultados discursivos meramente posibles en decisiones claras. El constitucionalismo discursivo se deriva de la teoría del discurso de Alexy, ya que esta teoría exige a los derechos fundamentales y a la democracia. ${ }^{132}$ Exige derechos fundamentales, pues la teoría del discurso se basa en la libertad y la igualdad. Y exige democracia, puesto que la idea misma de discurso solo puede realizarse en el mayor grado posible en una democracia deliberativa.

En su más reciente elaboración del aspecto sistemático de su trabajo, Alexy ha situado la tesis de la doble naturaleza en el centro de su filosofía del derecho. ${ }^{133} \mathrm{La}$ relevancia de la tesis de la doble naturaleza para el sistema de ALEXY ya se ha examinado en detalle anteriormente. Acá, es suficiente afirmar que, plausiblemente, esta tesis es la característica más importante del sistema de AleXY.

En suma, el enfoque fundamental del sistema de AlEXY puede describirse a través de tres características: liberalismo analítico, institucionalización de la razón y la tesis de la doble naturaleza. Cada una de estas características enfatiza aspectos importantes del trabajo de AleXY y están estrechamente conectadas entre sí. Como demostración de esta interconexión, dos aspectos pueden ser mencionados: el método analítico es en sí mismo una instancia de la institucionalización de la razón, ya que se centra en el método de la argumentación jurídica; y la incorporación de valores liberales fundamentales refleja la doble naturaleza del derecho.

El carácter de un sistema de filosofía del derecho se puede distinguir de varias maneras. Para subrayar el carácter principal de la filosofía del derecho de ALEXY, emplearé dos categorizaciones desarrolladas por Ralf Dreier. Primero, de acuerdo con Dreier, las teorías tienen un carácter analítico, normativo o empírico. ${ }^{134}$ Las teorías analíticas se centran en estructuras y conceptos generales del derecho. Las teorías empíricas describen y explican las estructuras y las relaciones funcionales del derecho desde un punto de vista empírico. Las teorías normativas abordan cuestiones de obligación o de

129. Alexy, 2001c: 686.

130. Alexy, 2007a: 1; AleXY, 2006: 1,17 y s.

131. Alexy, 2006: 18.

132. AleXy, 2007a: 3 y ss.

133. Ibid., 1.

134. Vid. Dreier, 1981: 84. 
evaluación de actos y condiciones jurídicas. En esta nomenclatura, la teoría de AlEXY es normativa y analítica. ${ }^{135}$

Segundo, Dreier diferencia las teorías integrales y segmentarias. ${ }^{136}$ Las teorías segmentarias explican solo aspectos individuales de un determinado objeto y emplean solo un punto de vista. Las teorías integrales, en cambio, intentan incluir tantos aspectos y puntos de vista como sea posible para adquirir una visión holística del objeto. La teoría de Alexy es una teoría integral en la medida en que combina los tres pilares de su trabajo, apuntando hacia un sistema de teoría del derecho.

Para ilustrar esto, podemos observar la teoría del discurso de Alexy. Alexy distingue una dimensión ideal y otra real. El discurso ideal está conectado con las ideas de racionalidad y corrección procesal absoluta. Esto, sin embargo, resulta ser una debilidad en lo que concierne a los discursos reales. Por lo tanto, la teoría del discurso puede desarrollarse en plenitud solo si se complementa con una teoría del Estado y del sistema jurídico que refleje la dimensión institucional y real del derecho. La relación entre el discurso ideal y los aspectos institucionales del discurso real es de dependencia mutua. Por lo tanto, la teoría plena de la racionalidad práctico-jurídica comprende tanto una teoría de un sistema de normas y una teoría de un sistema de procedimientos. ${ }^{137} \mathrm{El}$ punto importante aquí es que la teoría del discurso se establece en un sistema global de racionalidad práctica y, por lo tanto, en una teoría integral en el sentido de Dreier.

\section{CONCLUSIÓN}

En mi análisis de la filosofía del derecho de ALEXy, he llamado la atención sobre ciertas relaciones entre los tres pilares que le dan forma. La conexión más fundamental entre ellos puede encontrarse en la definición del concepto de derecho de Alexy al final de El Concepto y la Validez del Derecho:

El derecho es un sistema de normas que ... [comprende] los principios y los otros argumentos normativos en los que se apoya el procedmiento de la aplicación del derecho y/o tiene que apoyarse a fin de satisfacer la pretensión de corrección. ${ }^{138}$

La definición de derecho de AlEXY comprende principios, así como procesos de aplicación del derecho. ${ }^{139} \mathrm{La}$ conexión entre los tres pilares no puede ser más fuerte.

La pregunta subsiste: ¿es la filosofía del derecho de Alexy un sistema? De acuerdo con el significado de «sistema» empleado aquí, la respuesta es clara. La filosofía de AlEXY

135. Quine ha desafiado la posibilidad de estas diferenciaciones, vid. Quine, 2002. Para una defensa, vid. Grice y Strawson, 1956.

136. DREIER, 1981.

137. Vid. Alexy, 1991. Este punto ha sido descrito como una «teoría integral» por Brugger, vid. Brugger, 2000: 62 .

138. AleXY, 2004: 123.

139. Vid. ibid., 123-126. Esta definición global del concepto de derecho marca una diferencia importante con la teoría de Raz. Según RAz, los argumentos y principios en los que se basa o debe basarse el proceso de aplicación del derecho no son parte del derecho - de la etapa ejecutiva-, sino solo de la etapa deliberativa. 
cubre una amplia gama de preguntas fundamentales. Tiene un triple carácter, ya que combina análisis estructurales con elementos sustantivos y una teoría de la aplicación del derecho orientada a la práctica (use-oriented theory of law's application). ${ }^{140}$ Existen fuertes indicadores de que, de hecho, el todo es más que la suma de las partes. Si esto no cuenta como un sistema de filosofía del derecho, es difícil imaginar qué lo es.

\section{BIBLIOGRAFÍA}

Alexy, R., 1978: Theorie der juristischen Argumentation: Die Theorie des rationalen Diskurses als Theorie der juristischen Begründung, Frankfurt am Main: Suhrkamp.

Alexy, R., 1985: Theorie der Grundrechte, Baden-Baden: Nomos Verlagsgesellschaft.

Alexy, R., 1989: A Theory of Legal Argumentation, Oxford: Oxford University Press.

Alexy, R., 1991: «Idee und Struktur eines vernünftigen Rechtssystems», en R. Alexy, R. Dreier y U. Neumann (eds.), Rechts- und Sozialphilosophie in Deutschland heute, Stuttgart: Steiner, 30-44.

Alexy, R., 1992: Begriff und Geltung des Rechts, Freiburg/München: Alber.

Alexy, R., 1993: "Justification and Application of Norms», Ratio Juris, 6: 157-170.

Alexy, R., 1995a: «Teoría del Discurso y Derechos Humanos», Teoría del Discurso y Derechos Humanos, Bogotá: Universidad Externado de Colombia, 61-91.

Alexy, R., 1995b: «Vorwort», en Recht, Vernunft, Diskurs: Studien zur Rechtsphilosophie, Frankfurt am Main: Suhrkamp, 7-10.

Alexy, R., 1997: Teoría de la Argumentación Jurídica: La Teoría del Discurso Racional como Teoría de la Fundamentación Jurídica, Madrid: Centro de Estudios Políticos y Constitucionales.

Alexy, R., 1999: «La Tesis del Caso Especial», Isegoría, 21: 23-35.

Alexy, R., 2001a: «Una Defensa de la Fórmula de Radbruch», Anuario da Facultade de Dereito da Universidade da Coruña, 5: 75-96.

Alexy, R., 2001b: «Kollision und Abwägung als Grundprobleme der Grundrechtsdogmatik», World Constitutional Law Review, 6: 181-207.

Alexy, R., 2001c: «Entrevista a Robert Alexy» (por M. Atienza), Doxa. Cuadernos de filosofía del Derecho, 24: 671-687.

Alexy, R., 2003a: «Vorstellungsbericht», Jahrbuch der Akademie der Wissenschaften zü Göttingen: 326-331.

Alexy, R., 2003b: «Los Derechos Fundamentales en el Estado Constitucional Democrático», en M. Carbonell (ed.), Neoconstitucionalismo(s), Madrid: Trotta, 31-48.

Alexy, R., 2004: El Concepto y la Validez del Derecho, segunda edición, Barcelona: Gedisa.

Alexy, R., 2005a: «Acuerdos y Desacuerdos: Algunas Observaciones Introductorias», Anales de la Cátedra Francisco Suárez, 39: 729-735.

Alexy, R., 2005b: «Derecho y Corrección», La Institucionalización de la Justicia, Granada: Comares, 31-54.

140. Vid. Eriksen y Menendez, 2010: 13,21. Si bien los autores limitan su afirmación a la Teoría de los Derechos Fundamentales, en rigor, es plausible en un sentido más amplio, relacionada con el sistema que subyace a los trabajos de Alexy considerados como un todo. 
Alexy, R., 2006: «Ponderación, Control de Constitucionalidad y Representación», en R. Alexy у P. A. IвÁÑEz, Jueces y Ponderación Argumentativa, México: Instituto de Investigaciones Jurídicas, 1-18.

Alexy, R., 2007a: «Legal Philosophy: 5 Questions», en M. E. J. Nielsen (ed.), Legal Philosophy: 5 Questions, Nueva York: Automatic Press/VIP, 1-11.

Alexy, R., 2007b: «¿Derechos Humanos sin Metafísica?», Doxa, 30: 237-248.

Alexy, R., 2008a: Teoría de los Derechos Fundamentales, segunda edición, Madrid: Centro de Estudios Políticos y Constitucionales.

Alexy, R., 2008b: «La Naturaleza de la Filosofía del Derecho», El Concepto y la Naturaleza del Derecho, Madrid: Marcial Pons, 35-50.

Alexy, R., 2008c: «La Naturaleza de los Argumentos sobre la Naturaleza del Derecho», El Concepto y la Naturaleza del Derecho, Madrid: Marcial Pons, 51-72.

Alexy, R., 2008d: «En Torno al Concepto y la Naturaleza del Derecho», El Concepto y la Naturaleza del Derecho, Madrid: Marcial Pons, 73-98.

Alexy, R., 2009a: «Los Principales Elementos de mi Filosofía del Derecho», Doxa 32: 68-84.

Alexy, R., 2009b: «Hauptelemente einer Theorie der Doppelnatur des Rechts», Archiv für Rechts- und Sozialphilosophie, 95: 151-166.

Alexy, R., 2010: «La Teoría del Discurso y los Derechos Fundamentales», en E. O. Eriksen y A. J. Menéndez (eds.), La Argumentación y los Derechos Fundamentales, Madrid: Centro de Estudios Políticos y Constitucionales, 29-50.

Alexy, R., 2011a: «La Doble Naturaleza del Derecho», en C. Bernal Pulido (ed.), La Doble Dimensión del Derecho: Autoridady Razón en la Obra de Robert Alexy, Lima: Palestra, 29-58.

Alexy, R., 2011b: «Algunas Reflexiones en torno a cómo mi Pensamiento Jurídico ha ido Desarrollándose con el Paso de los Años», en C. Bernal Pulido (ed.), La Doble Dimensión del Derecho: Autoridad y Razón en la Obra de Robert Alexy, Lima: Palestra, 59-87.

Alexy, R., 2013a: «Una Respuesta a Joseph Raz», en G. Pavlakos (ed.), Derecho, Derechos y Discurso, Bogotá: Universidad Externado de Colombia, 61-85.

Alexy, R., 2013b: «El No Positivismo Incluyente», Doxa, 36: 15-23.

Alexy, R., 2014: «De la Ponderación y la Subsunción: Una Comparación Estructural», en E. Montealegre, N. Bautista y L. F. Vargas (eds.), La Ponderación en el Derecho: Evolución de una Teoría, Aspectos Criticos y Ámbitos de Aplicación en el Derecho Alemán, Bogotá: Universidad Externado de Colombia, 39-62.

Alexy, R., 2015: «Legal Certainty and Correctness», Ratio Juris, 28: 441-451.

Alexy, R., 2017: "The Ideal Dimension of Law», en G. Duke y R. P. George (eds.), The Cambridge Companion to Natural Law Jurisprudence, Cambridge: Cambridge University Press, 314-341.

Alexy, R., 2019a: «Sobre la Estructura de los Principios Jurídicos», Ensayos sobre la Teoría de los Principios y el Juicio de Proporcionalidad, Lima: Palestra, 55-75.

Alexy, R., 2019b: "Las Normas de Derecho Fundamental y los Derechos Fundamentales», Ensayos sobre la Teoría de los Principios y el Juicio de Proporcionalidad, Lima: Palestra, 77-90.

Alexy, R., 2019c: "Los Derechos Fundamentales, la Ponderación y la Racionalidad», Ensayos sobre la Teoría de los Principios y el Juicio de Proporcionalidad, Lima: Palestra, 107-117.

Alexy, R., y Marmor, A., 2005: «La Separación entre el Derecho y la Moral: Debate entre R. Alexy y A. Marmor», Anales de la Cátedra Francisco Suárez, 39: 743-768. 
Brandom, R., 2005: Hacerlo Explícito: Razonamiento, Representación y Compromiso Discursivo. Barcelona: Herder.

Braun, C., 1988: "Diskurstheoretische Normenbegründung in der Rechtswissenschaft», Rechtstheorie, 19: 238-261.

Brożek, B., 2013: «La Fórmula del Peso y la Argumentación», en G. Pavlakos (ed.), Derecho, Derechos y Discurso, Bogotá: Universidad Externado de Colombia, 413-428.

DreIER, R., 1981: «Zur Theoriebildung in der Jurisprudenz», Recht-Moral-Ideologie: Studien zur Rechtstheorie, Frankfurt am Main: Suhrkamp, 70-105.

Dwars, I., 1992: "Application Discourse and Special Case Thesis», Ratio Juris, 5: 67-78.

Eriksen, E. O., y Menéndez, A.J., 2010: «Introducción», en La Argumentación y los Derechos Fundamentales, E. O. Eriksen y A. J. Menéndez (eds.), Madrid: Centro de Estudios Políticos y Constitucionales, 11-26.

García Figueroa, A., 2009: «¿Existen Diferencias entre Reglas y Principios en el Estado Constitucional? Algunas Notas sobre la Teoría de los Principios de Robert Alexy», en R. García Manrique (ed.), Derechos Sociales y Ponderación, segunda edición, Madrid: Fundación Coloquio Jurídico Europeo, 333-370.

Grice, H. P., y Strawson, P. F., 1956: «In Defense of a Dogma», The Philosophical Review, 65: 141-158.

Günther, K., 1993: «Critical Remarks on Robert Alexy’s Special Case Thesis», Ratio Juris, 6: 143-156.

Habermas, J., 1995: «Reply to Symposium Participants», Cardozo Law Review, 17: 1477-1557.

Habermas, J., 2005: Facticidad y Validez: Sobre el Derecho y el Estado Democrático de Derecho en Términos de Teoría del Discurso, cuarta edición, Madrid: Trotta.

Hart, H. L. A., 1962: «El Positivismo Jurídico y la Separación entre el Derecho y la Moral», Derecho y Moral: Contribuciones a su Análisis, Buenos Aires: Ediciones Depalma, 1-64.

Herget, J. E., 1996: Contemporary German Legal Philosophy, Philadelphia: University of Pennsylvania Press.

Hilgendorf, E., 2005: Die Renaissance der Rechtstheorie zwischen 1965 und 1985, Würzburg: Ergon Verlag.

Kant, I., 2009: Crítica de la Razón Pura, México: Fondo de Cultura Económica.

Kaufmann, A., 1989: «Läßt sich die Hauptverhandlung in Strafsachen als rationaler Diskurs auffassen?», en H. Jung y H. Müller-Dietz (eds.), Dogmatik und Praxis des Strafverfahrens, Köln: Carl Heymanns, 15-24.

Kaufmann, A., 1992: "Panorámica Histórica de los Problemas de la Filosofía del Derecho», en W. Hassemer y A. Kaufmann (eds.), El Pensamiento Jurídico Contemporáneo, Madrid: Debate, 47-141.

KLAtT, M., 2007: «Contemporary Legal Philosophy in Germany», Archiv für Rechts- und Sozialphilosophiem, 93: 519-539.

KLATt, M., 2009: «Aleksander Peczenik über die Rationalität der juristischen Argumentation», en A. Brockmöller y E. Hilgendorf (eds.), Rechtsphilosophie im 20. Jahrhundert: 100 Jahre Archiv für Rechts- und Sozialphilosophie, Sttutgart: Steiner, 187-207.

Klatt, M., 2011: "Tomar los Derechos no tan en Serio: Un Análisis Estructural de la Discrecionalidad Judicial», en G. A. BeAde y L. Clérico (eds.), Desafíos a la Ponderación, Bogotá: Universidad Externado de Colombia, 485-536. 
Klatt, M., 2017: Hacer el Derecho Explícito: Normatividad Semántica en la Argumentación Juridica. Madrid: Marcial Pons.

Косн, H., 1988: «Zur Methodenlehre des Rechtspositivismus», en R. Dreier (ed.), Rechtspositivismus und Wertbezug des Rechts, Stuttgart: Steiner, 152-161.

Kumm, M., 2004: «Constitutional Rights as Principles: On the Structure and Domain of Constitutional Justice. A Review Essay on a Theory of Constitutional Rights», International Journal for Constitutional Law, 2: 574-596.

MacCormick, N., 1982: «Legal Reasoning and Practical Reason», Midwest Studies in Philosophy, 7: 271-286.

Neumann, U., 1986: Juristische Argumentationslehre, Darmstadt: Wissenschaftliche Buchgesellschaft.

Neumann, U., 1996: «Zur Interpretation des forensischen Diskurses in der Rechtsphilosophie von Jürgen Habermas», Rechtstheorie, 27: 415-426.

Pavlakos, G., 1998: "The Special Case Thesis: An Assessment of Robert Alexy's Discursive Theory of Law», Ratio Juris, 11: 126-154.

Pavlakos, G., 2013: «Introducción», en G. Pavlakos (ed.), Derecho, Derechos y Discurso, Bogotá: Universidad Externado de Colombia, 17-32.

Poscher, R., 2007: «Einsichten, Irrtümer und Selbstmissverständnis der Prinzipientheorie», en J. R. Sieckmann (ed.), Die Prinzipientheorie Der Grundrechte: Studien Zur Grundrechtstheorie Robert Alexys, Baden-Baden: Nomos, 59-80.

Quine, W. V. O., 2002: «Dos Dogmas del Empirismo», en Desde un Punto de Vista Lógico, Madrid: Paidós, 61-91.

Rawls, J., 1995: Teoría de la Justicia. México: Fondo de Cultura Económica.

RAz, J., 1995: «El Problema de la Naturaleza del Derecho», Isonomía: Revista de Teoría y Filosofía del Derecho, 3: 131-151.

Raz, J., 2013a: «El Argumento de la Justicia, o cómo no Replicar al Positivismo Jurídico», en G. Pavlakos (ed.), Derecho, Derechos y Discurso, Bogotá: Universidad Externado de Colombia, 35-59.

RAz, J., 2013b: «Sobre la Naturaleza del Derecho», Entre la Autoridad y la Interpretación: Sobre la Teoría del Derecho y la Razón Práctica, Madrid: Marcial Pons, 103-136.

RAz, J., 2013c: «La Incorporación por el Derecho», Entre la Autoridad y la Interpretación: Sobre la Teoría del Derecho y la Razón Práctica, Madrid: Marcial Pons, 193-212.

Schauer, F., 1997: «Prescriptions in Three Dimensions», Iowa Law Review, 82: 911-922

Schauer, F., 2004: Las Reglas en Juego: Un Examen Filosófico de la Toma de Decisiones basada en Reglas en el Derecho y en la Vida Cotidiana. Madrid: Marcial Pons.

$\triangle \quad$ DOXA $43(2020)$

Doxa. Cuadernos de Filosofía del Derecho, (2020), 43, pp. 219-252 